\title{
Reese-Ellsworth Classification IB
}

National Cancer Institute

\section{Source}

National Cancer Institute. Reese-Ellsworth Classification IB. NCI Thesaurus. Code

C123369.

Multiple tumors, none larger than 4 disc diameters, all tumors at or behind the equator. 